\title{
COMPORTAMENTO E CINÉTICA DO TINGIMENTO DE ALGODÃO COM BORRA DE VINHO DA UVA TEROLDEGO
}

\author{
D. $\mathrm{KUHN}^{1}$, G. CESCONETO ${ }^{1}$ e C.R.L. AGUIAR ${ }^{1}$ \\ ${ }^{1}$ Universidade Federal de Santa Catarina, Departamento de Engenharias \\ E-mail para contato: catia.lange@ufsc.br
}

\begin{abstract}
RESUMO - A indústria têxtil é grande consumidora de corantes sintéticos para a realização dos tingimentos de seus produtos. Consequentemente, estes corantes percorrem um caminho em sistemas públicos de água, represas, lagos, rios e mar como resultado de efluentes industriais e domésticos. Embora as cores exigidas pelo mercado mundial de moda sejam facilmente obtidas com o uso de corantes sintéticos, o emprego de alguns corantes naturais pode ser uma prática aceita e sustentável. Diante dos impactos ambientais causados pelo descarte de corantes da indústria têxtil, observa-se um problema ambiental. Para diminuir ou até mesmo anular estes impactos uma alternativa são os corantes naturais, que podem em alguns casos, assemelhar-se ou mesmo superar, os corantes sintéticos. Assim, diante da problemática citada, o estudo tem como objetivo tingir tecidos de algodão utilizando borra de vinho tinto de uva Teroldego, visando a obtenção de uma alternativa para o emprego de corantes naturais em tingimentos têxteis, bem como a redução de impactos ambientais significativos.
\end{abstract}

\section{INTRODUÇÃO}

Cada vez mais o mundo da moda dita cores, texturas, modelagens e formas diversas para os mais variados artigos têxteis de vestuário, decoração e outras aplicações. Para atender estes anseios e respeitar as questões ambientais, pesquisas relacionadas a busca por elementos naturais e preferencialmente por elementos que apresentem baixos impactos ambientais são importantes e necessárias.

O tingimento de substratos têxteis é uma antiga arte e por muitos séculos foram empregados corantes naturais, por métodos totalmente empíricos (Salem, 2010). De acordo com Pezzolo (2009), a garança e o pastel foram dois principais corantes usados na Idade Média (476 a 1453), onde também se usava o quermes dos tintureiros, semelhante à cochonilla, que resulta numa tintura vermelha, e a gauda, em uma tonalidade verdeamarelada. Porém, para atender ao mercado de moda, que exige cores diferenciadas, com diferentes intensidades e brilho, a utilização de corantes naturais em aplicações têxteis, de forma industrial, sofreu importante queda. Para que possam ser considerados, suas propriedades vem sendo estudadas tanto em tecidos naturais quanto em sintéticos por Adeel, et. al. (2017).

Um dos problemas encontrados quando os substratos são tingidos com corantes naturais é a baixa solidez ao uso e tratamentos posteriores, como lavações, exposição à luz e outros. Para que este problema seja minimizado, alguns pesquisadores já vem apresentando resultados positivos, como é o caso do estudo de Baliarsingh (2012), que concluiu que fios de 
seda tintos com corantes naturais exibiram propriedades elevadas de solidez de cor e um bom efeito antimicrobiano.

Embora as cores exigidas pelo mercado mundial de moda sejam facilmente obtidas com o uso de corantes sintéticos, o emprego de alguns corantes naturais pode ser uma prática aceita e sustentável. Estudos vem apresentado elementos naturais utilizados como corantes, tais como os obtidos de alfafa, da garança, do pau Campeche e do Urucum, conforme apresentado por Piccoli (2008), bem como cascas de barbatimão, sementes de café moídas, erva mate, urucum em pó, frutos de jenipapo e cascas de cebola (Damasceno et al., 2010).

Como alternativa, outro pigmento que vem sendo estudado são as antocianinas, presentes nas cascas de uva e seus subprodutos, como a borra de produção de vinho tinto. $\mathrm{O}$ estudo de Silva (2016) mostrou que estas borras podem ser aproveitadas para extração de diversos elementos, dentre eles, a matéria corante. Considerando esta afirmação, o presente estudo, tem como objetivo investigar o comportamento tintorial do pigmento presente na borra de vinho de uvas Teroldego sobre um substrato composto de fibras de $100 \%$ algodão, a interferência de métodos de preparação prévia das fibras, a cinética de tingimento e a solidez a lavação.

\section{METODOLOGIA}

A borra de vinho, utilizada como corante foi obtida do resíduo da produção do vinho tinto Terodelgo, resultante de $2^{a}$ filtração, da Vinícola San Michele, em Rodeio, SC - Brasil. Como corante, não efetuada nenhuma extração das antocianinas da borra, somente foi efetuada uma filtração simples, onde foi separado o líquido do sólido da mistura. O líquido foi denominado neste estudo como corante líquido e o sólido como corante pó. Como substrato têxtil, foi utilizado tecido de meia malha de $100 \%$ algodão sem tratamento. Para a realização dos tingimentos o corante foi aplicado na forma líquida filtrada e na forma pó.

Para a realização dos tingimentos, foram empregados os processos e formulações, conforme apresentado no Quadro 1.

Quadro 1: Processos de preparação e formulações de tingimento

\begin{tabular}{|c|c|c|}
\hline Item & Formulação & Processo de preparação \\
\hline 1 & $50 \%$ corante líquido & Nenhum \\
\hline 2 & $\begin{array}{c}50 \% \text { corante líquido }+80 \mathrm{~g} / \mathrm{L} \text { de cloreto de } \\
\text { sódio }\end{array}$ & Purga \\
\hline 3 & $\begin{array}{c}50 \% \text { corante líquido }+80 \mathrm{~g} / \mathrm{L} \text { de cloreto de } \\
\text { sódio }\end{array}$ & Pré-alvejamento \\
\hline 4 & $50 \%$ corante pó $+80 \mathrm{~g} / \mathrm{L}$ de cloreto de sódio & Pré-alvejamento \\
\hline 5 & $25 \%$ corante pó $+80 \mathrm{~g} / \mathrm{L}$ de cloreto de sódio & Pré-alvejamento \\
\hline
\end{tabular}


Como preparação prévia do substrato para tingimento, foram efetuados processos de purga e pré-alvejamento. O processo de purga foi realizado em temperatura de $80{ }^{\circ} \mathrm{C}$ durante 30 minutos com $2 \mathrm{~g} / \mathrm{L}$ de detergente aniônico e $1 \mathrm{~g} / \mathrm{L}$ Barrilha. O processo de pré-alvejamento foi realizado em temperatura de $90{ }^{\circ} \mathrm{C}$ durante 30 minutos com $2 \mathrm{~g} / \mathrm{L}$ detergente aniônico, 2 $\mathrm{g} / \mathrm{L}$ de emulgador, $4 \mathrm{~g} / \mathrm{L}$ de Barrilha e $4 \mathrm{~g} / \mathrm{L}$ de Peróxido de Hidrogênio (50\%).

Após cada um dos processos de preparação, os tecidos foram lavados com água limpa e corrente até completa remoção da alcalinidade. Os processos de tingimento foram realizados em erlenmayer, em shaker com rotação de $100 \mathrm{rpm}$, em temperatura de $60{ }^{\circ} \mathrm{C}$ durante 60 minutos e não sofreram nenhuma lavação após o processo. Os corantes e auxiliares de tingimento foram adicionados à solução, em seguida foi inserido o substrato e então iniciado o processo de tingimento.

A solidez a lavação a $40{ }^{\circ} \mathrm{C}$ para avaliar alteração e transferência de cor foi realizada conforme norma ABNT NBR ISSO 105-A03, porém com o uso de detergente comercial alcalino.

Para a determinação da cinética do tingimento, foi realizado o tingimento conforme amostra 5 do quadro 1. A absorbância foi determinada utilizando-se comprimento de onda de $278 \mathrm{~nm}$ em espectrofotômetro Micronal, modelo AJX 1900.

\section{RESULTADOS}

Após a realização dos processos apresentados, os resultados de concentração de cor das amostras tingidas foram $100 \%, 108,87 \%, 122,98 \%, 129,86 \%$ e $59,59 \%$ respectivamente.

A amostra 1 é considerada a cor padrão. A partir dos resultados obtidos, é possível afirmar que os processos de preparação do substrato têxtil antes do tingimento interfere no resultado da absorção do corante por parte do tecido de algodão. Percebeu-se um aumento de $8,87 \%$ de absorção de corante nos tecido purgado e $22,98 \%$ no tecido pré-alvejado, indicando que o pré-alvejamento é o melhor processo de preparação do tecido de algodão no tingimento com o corante natural proveniente da borra de vinho Teroldego após filtração. Quando avaliou-se a variação da quantidade inicial de corante empregado, também pode-se observar que a relação concentração inicial de corante e intensidade de cor final é proporcional, o que indica que a quantidade de antocianinas presentes na solução é absorvida pelo substrato, demonstrando que diferentes intensidades de cor podem ser obtidas.

Ao realizar a avaliação da solidez à transferência, todas as amostras atingiram nota 4/5 com relação à escala cinza, que possui nota máxima 5. Quando as amostras foram avaliadas levando-se em consideração a solidez a alteração, os resultados não foram satisfatórios e podem ser observados na figura 1 . 


\section{Congresso Brasileiro de Engenharia Química em Iniciação Científica UFSCar - São Carlos - SP 16 a 19 de Julho de 2017}

Figura 1: Resultados dos tingimentos e ensaios de solidez a lavação a $40^{\circ} \mathrm{C}$, alteração.

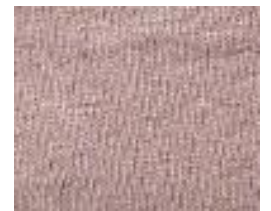

Amostra 1 (tingimento)

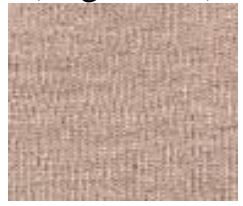

Amostra 1 (alteração)

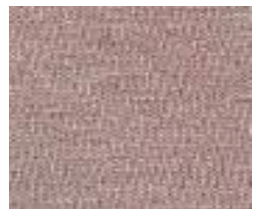

Amostra 2 (tingimento)

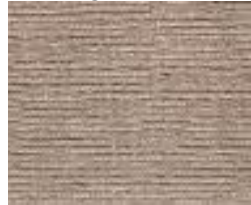

Amostra 2 (alteração)

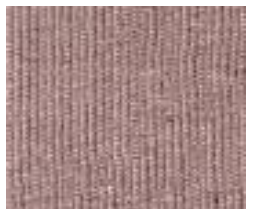

Amostra 3
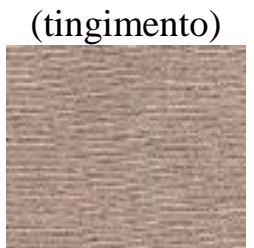

Amostra 3

(alteração)

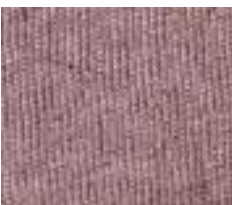

Amostra 4 (tingimento)

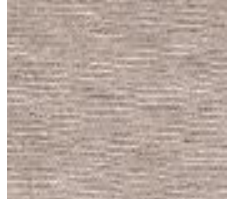

Amostra 4

(alteração)

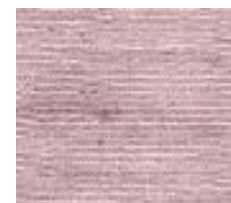

Amostra 5 (tingimento)

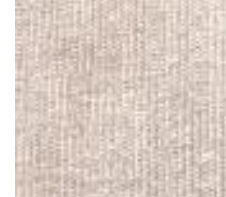

Amostra 5

(alteração)

Para todos os tingimentos, com preparações diferentes, os tecidos apresentaram considerável alteração de cor. Como os tecidos foram lavados com sabão em pó comercial em $\mathrm{pH}$ levemente alcalino, este comportamento é justificado, pois as antocianinas possuem como característica a alteração de cor de acordo com a variação de $\mathrm{pH}$, onde as soluções contendo pigmentos com $\mathrm{pH}$ acima de 7,0, gradualmente mudam a coloração de tonalidade azul para amarela, como um resultado indireto da formação de chalcona (Lopes et al., 2007).

Ao avaliar a cinética de tingimento, observou-se que após 40 minutos o tingimento atinge o equilíbrio, como pode ser visto na Figura 2.

Figura 2: Cinética de tingimento

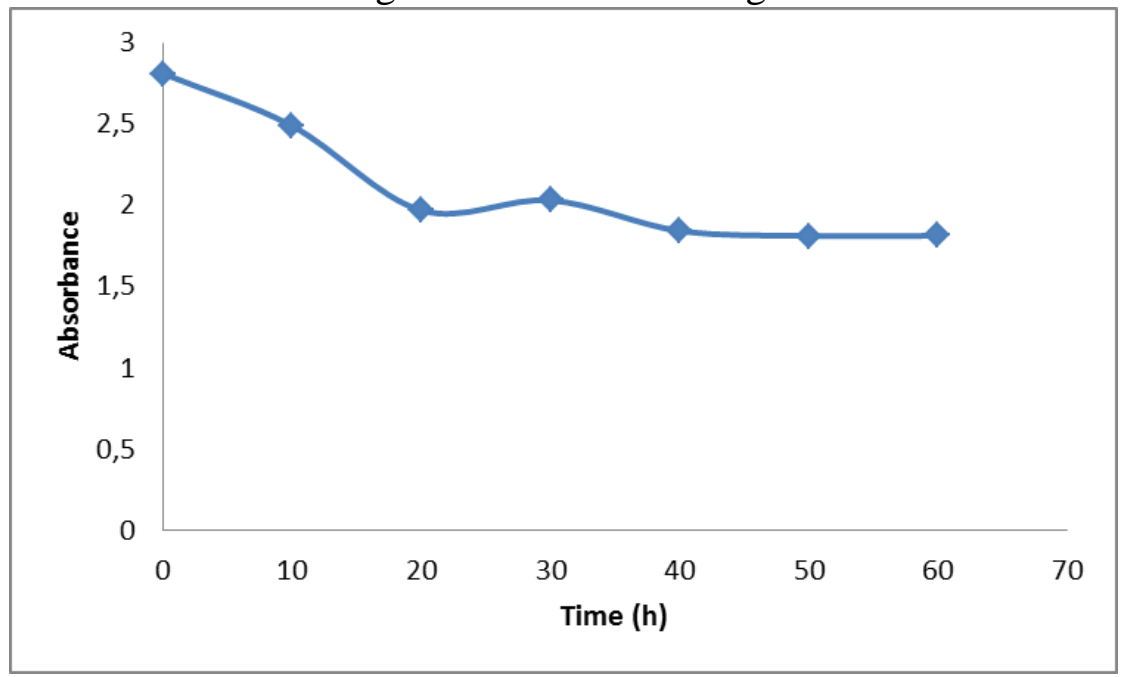

Neste momento o tingimento deixa a fase cinética, onde há a aproximação do corante na fibra e sua adsorção através das regiões amorfas do algodão, para a fase termodinâmica do tingimento, onde o corante difunde no interior da fibra e fixa-se a esta. 


\section{CONCLUSÃO}

O presente estudo avaliou a capacidade de tingimento de um substrato têxtil de $100 \%$ algodão com os pigmentos obtidos da borra de produção de vinho com uvas Teroldego. Foi observado que os resultados de intensidade de cor são mais expressivos quando a preparação prévia do material é efetuada o com processo de pré-alvejamento. Os resultados dos ensaios de solidez a lavagem a $40{ }^{\circ} \mathrm{C}$ indicaram excelentes valores de solidez a transferência, onde o corante não migra do substrato tinto para o substrato branco, porém os resultados de alteração de cor após processos de lavagem são insatisfatórios, indicando que há a necessidade de maiores estudos com este corante sobre o substrato de $100 \%$ algodão. Ao avaliar a cinética de tingimento, percebe-se que o sistema entra em equilíbrio a partir de 40 minutos, porém, como em tingimentos com corantes sintéticos, é importante manter o sistema por mais tempo para garantir a fixação do corante na fibra. Os resultados indicam que há necessidade de continuidade dos estudos com aplicação de mordentes e extração das antocianinas da solução inicial para novos processos de tingimento.

\section{AGRADECIMENTOS}

Os autores agradecem ao CNPq pela bolsa Pibic.

\section{REFERÊNCIAS}

ADEEL, S., GULZAR, T., AZEEM, M., REHMAN, F., SAEED, M., HANIF, I., IQBAL, N. Appraisal of marigold flower based lutein as natural colourant for textile dyeing under the influence of gamma radiations. Radiation Physics and Chemistry, v. 130, p. 35-39, 2017.

BALIARSINGH, S., PANDA, A.K., JENA, J.i, DAS, T., DAS, N.B. Exploring sustainable technique on natural dye extraction from native plants for textile: identification of colourants, colourimetric analysis of dyed yarns and their antimicrobial evaluation. Journal of Cleaner Production. V. 37, p. 257-264, 2012.

DAMASCENO, Silvia M. B., SILVA, Fernanda T. F., FRANCISCO, Antonio C. Sustentabilidade do processo de tingimento do tecido de algodão orgânico. XXX Encontro Nacional de Engenharia de Produção, São Carlos, 2010.

LOPES, T.J., XAVIER, M.F., QUADRI, M.G.N., QUADRI, M. Antocianinas: uma breve revisão das características estruturais e da estabilidade. Revista Brasileira de Agrociências, v. 13, p. 291-297, 2007.

PEZZOLO, D.B. Tecidos. Tecidos: história, tramas, tipos e usos. São Paulo: Editora SENAC, 2007.

PICCOLI, H.H. Determinação do comportamento tintorial de Corantes naturais em substrato de algodão. Dissertação de Mestrado, Florianópolis, 2008.

SALEM, V. Tingimento Têxtil: fibras, conceitos e tecnologias. São Paulo: Editora Blucher, 2010.

SILVA, Luís M. L. R. Caracterização dos subprodutos da vinificação. Disponível em: http://www.ipv.pt/millenium/Millenium28/10.pdf, acesso em: 25/abril/2016. 